\title{
Professional Development On-line: Ways of Knowing and Ways of Practice
}

\author{
Sandra Shaw Courter, Cid Freitag, Mary McInery \\ University of Wisconsin - Madison
}

\begin{abstract}
"Ways of Knowing and Ways of Practice" is an on-line professional development opportunity for faculty and instructional staff at the University of Wisconsin - Madison. This pilot distance learning experience occurred during Spring Semester, 2003. The project was designed to help faculty 1) engage in reflection and continuous improvement of learning, both their own and their students, 2) facilitate conversations about teaching and learning in the process of building a learning community, 3) create a collaborative learning environment with faculty and peers, 4) build confidence in curriculum development including designing, guiding, and assessing learning, 5) learn with and about technology in the process of improving curriculum, and 6) connect teaching and research and bridge the gap between theory and practice. The twenty participants represented ten universities; a team of two from each university included one faculty person from engineering and one from another science, math, or computer science discipline. Specifically, the professional development opportunity explored ways of knowing including theories of learning, learning styles, disciplinary and cultural perspectives and how they inform ways of practice including both teaching practice and engineering practice. After an orientation in Madison, Wisconsin, the experience involved weekly on-line discussions based on readings, a personalized curriculum project, and approximately two to three hours per week commitment on the part of each participant. The Foundation Coalition funded this project. This paper highlights the assessment results of this pilot project and next steps based on analysis and reflection. A forth-coming mini-document will describe how to develop and implement a distancebased faculty development program.

\section{Description and Implementation}

During the Spring 2003, 20 faculty representing ten teaching and research universities throughout the country participated in a pilot on-line professional development experience, Ways of Knowing: Ways of Practice. The following institutions were represented:

Dordt College

Michigan State University

Milwaukee School of Engineering

North Dakota State University

Southeast Missouri State

Proceedings of the 2004 American Society for Engineering Education Annual Conference \& Exposition

Copyright 2004 American Society for Engineering Education
\end{abstract}


Southern Illinois University—Edwardsville

Tarleton State University

University of Minnesota-Duluth

University of Wisconsin-Madison

University of Wisconsin-Platteville

At each institution, two faculty were selected to participate in the on-line experience; in each of the ten cases, the team consisted of one engineering faculty member and one nonengineering faculty member. The teleconference sessions included sessions initially led by the lead facilitator from the host institution (University of Wisconsin-Madison), but then led by individuals from the participating institutions; these individuals were also known as facilitators. Their role was to design the weekly conversation based on a topic of their choice and a reading that they made available in advance. Faculty participants developed a project and presented the project at the end of the semester.

The research-based program for professional and organizational development builds on key concepts in professional development and organizational learning including Schon's reflective practice ${ }^{1}$, Argyris' organizational learning ${ }^{2}$, Wenger's communities of practice $^{3}$, Senge's learning organizations ${ }^{4}$, and Bransford's nature of expertise ${ }^{5}$. For example, the proposed program incorporates the key components from Argyris' approach: problem identification, context, brainstorm, solution, implementation, and reflection. While engineers have come to appreciate the design process that also incorporates these same steps, as professionals we often do not apply or adapt these steps to our own lives. When a problem related to teaching and learning surfaces, we often skip the key steps of identifying context, brainstorming, and reflecting, and move directly from problem to solution and implementation.

In addition, the pilot provided an opportunity to build a community of faculty committed to learning. Consistent with Wenger's description of a "community of practice" as described by Hildreth and Kimble, ${ }^{6}$ the experience included the following characteristics: 1) shared practices. Participants were linked to each other through their involvement in certain common activities including the residential three-day orientation. 2) shared repertoire of resources. Participants identified and posted readings, software, and websites plus their powerpoint slides for their weekly conversation and their projects. 3) common ground. Participants all were faculty in engineering, math, or science within higher education institutions. 4) common purpose and motivation. Participants shared their interest in improving student learning in higher education. 5) relationship. Participants developed professional relationships among themselves based on their shared backgrounds, practices, and interests; these relationships led to trust among themselves and identity with the Ways of Knowing experience. 6) narration. Participants shared stories about their students and classrooms; this story-telling is useful in both sharing and generating knowledge. 7) level of formality. Participants worked within the formal constraints of a weekly conversation at a designated time but every attempt was made to make each conversation informal despite the fact that each individual was sitting in his or her own office "at a distance." 
The online professional development experience consisted of several components. First, the cross campus and disciplinary identity of the participants was the pairing of engineering and non-engineering faculty from each institution. Second, the participants shared a belief in and practice of continuous improvement for both their teaching and their students' learning. Third, the research-based discussion included the participants identifying articles related to issues that they were investigating to see what others had done on similar issues. Finally, time set aside for professional development was a critical component.

The model included expected learning outcomes that participants' feedback affirmed. Participants increased self-reflection on teaching, collaboration with other educators, confidence in curriculum design, use of research in teaching, and knowledge about technology in teaching. Figure 1 describes the main components and the learning outcomes of the online experience.

Figure 1: Model for Ways of Knowing, Ways of Practice

On-line Experience Components

\section{Expected Outcomes}

Increased....

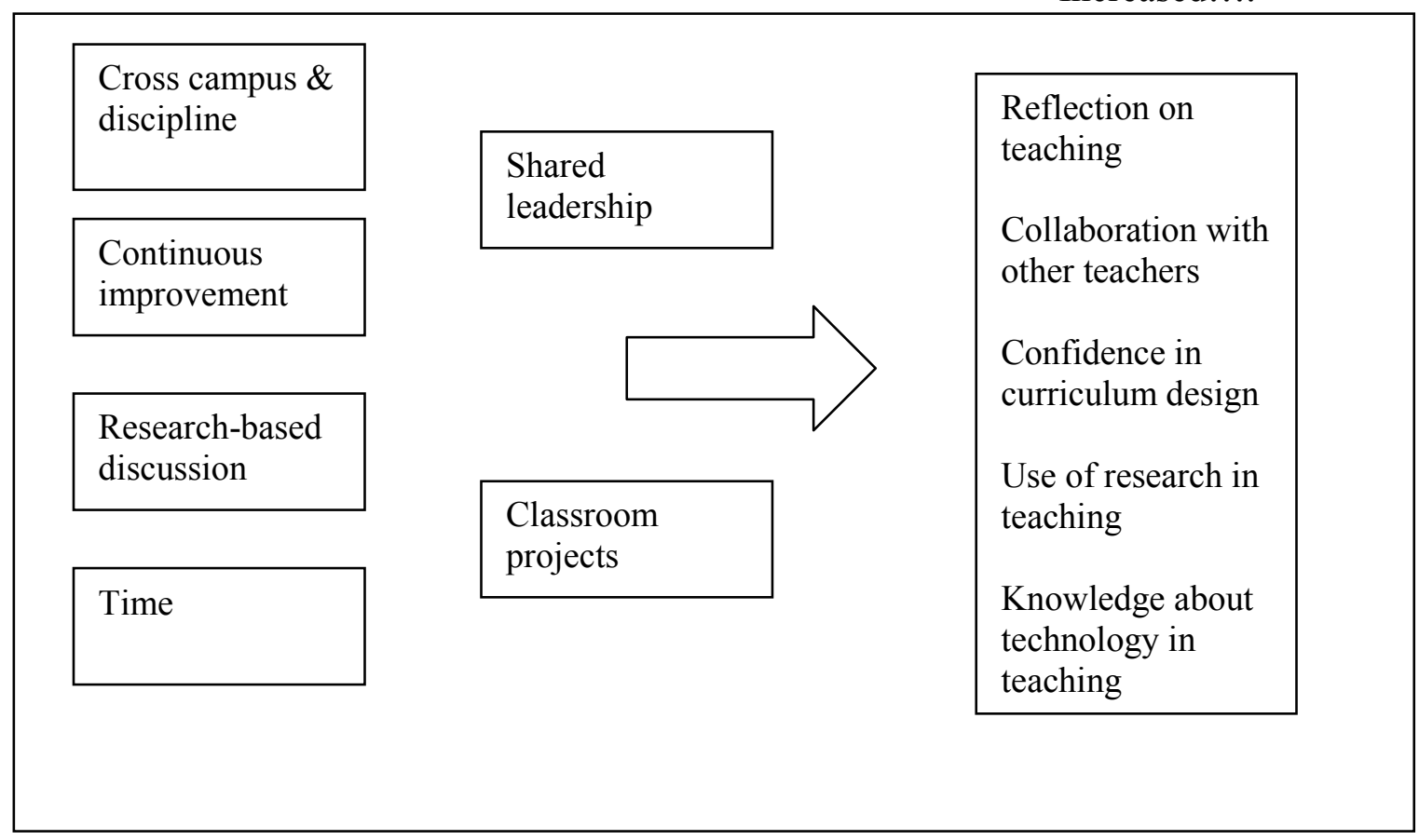

The professional development objectives for the on-line experience were to...

1. Facilitate challenging conversation about and construct a richer understanding of teaching and learning

2. Use technology to share perspectives and pose provocative questions about issues of teaching and learning in higher education

3. Build an effective learning community

Proceedings of the 2004 American Society for Engineering Education Annual Conference \& Exposition 
4. Articulate a personal teaching and learning philosophy

5. Propose and make progress on a teaching and learning project

\section{Research-based, Real-world Projects}

All participant teams completed an investigation into a teaching and learning issue; this experience became known as a "project." All projects focused on pedagogical issues rather than content issues, as expected; that is, participants were interested in methods and activities that would lead to improved student understanding of concepts. While both team members agreed on the issue, their applications were different depending on the course the individual was teaching. For example, while one team was investigating computer simulation software, they had different applications for the software in different courses and with different students. One application was in fluid mechanics course and the concept involved the Bernoulli equation; the other application was in a material/energy balance course and the concept involved transient energy transfer. Each team focused on their project throughout the experience, worked independently to make progress, applied new knowledge gained from weekly readings and conversations, and presented their progress during one of the last two weekly on-line conversations.

All submitted a one-page summary including a project description, assessment plan, results, and next steps; some added resources. The topics are listed below as examples for participants in future programs.

- Introduction to computer and software engineering course incorporating LEGO Mindstorm Labs

- Using computers in laboratory: computers interfaced to physics laboratory measurement equipment and computers simulating the use of measurement equipment

- Using computer simulation software to help students understand specific concepts

- Using Group Instructional Feedback Technique to assess how students were reacting to the "active" classrooms both professors strive to create

- Assessing educators about overall recommendations of NRC Report on teaching effectiveness

- Creating and testing a "time log" to better understand how faculty spend time in research, teaching, professional development, and service plus assessing student learning associated with various teaching tasks

- Creating and delivering illustrations/graphics for better student understanding

- Building collaborative teams of engineering and education students to design and test science projects for early childhood through grade four students

- Comparing traditional courses with web-based courses

- Testing the merits of experiential learning, also known as situated learning in terms of both student and faculty learning

Observation and survey data indicated that all projects either have had or will have a significant impact within the institution, based on a scale of none, little, some, and significant impact. See the website for project reports. http://www.engr.wisc.edu/services/elc/waysknow.htm.

Proceedings of the 2004 American Society for Engineering Education Annual Conference \& Exposition 


\section{How technology was used}

Most of the faculty's participation was done at a distance, using multiple communication tools. These included mail, email and telephone, and tools developed specifically for online-based cohort communications. These tools were WisLine Web, a browser-based teleconferencing system and WebCT, a course management system.

WisLine Web* is a teleconferencing service offered through the University of Wisconsin-Extension. These teleconferences integrated dialog, presentation slides, interactive tools, used by participants at a distance, and in real time. The presentation options included text slides, photographs, live web browsing, polling, application demonstration and sharing, digital whiteboard, and text chat. These tools, combined with live telephone-based audio, were intended to allow the faculty to interact and stay in contact with the other participants and to stay engaged with the content.

Facilitators were encouraged to make use of the interactive tools and included annotation, polling, and software demonstrations with their content. Presenters controlled when and how the content was delivered and when and how participants could interact with the presentation tools.

Faculty participated in weekly web-browser-based teleconference conversations of approximately one hour each. Conversations were scheduled at two time slots each week to better accommodate participants' schedules. Participants had a choice of which one session to attend each week. Activities included group discussions, question and answer sessions, project presentations and discussions with guest speakers and outside experts.

*Note: PlaceWare, the web-based visual and interactive component of the WisLine Web sessions has since been purchased by Microsoft and is now named "Microsoft Office Live Meeting"

WebCT(World Wide Web Course Tools) is a web-based course management system, available at the University of Wisconsin-Madison during Spring 2003**. It uses a web browser as the interface for both building and accessing on-line course materials. WebCT offers tools useful for course delivery and management, including a course calendar, electronic mail, gradebook, auto-marked quizzes, and more. The WebCT tools used during the "Ways of Knowing and Ways of Practice" experience consisted of text content, URL links, and bulletin-board style discussions that could include document exchange. Participants were encouraged to $\log$ in to the site twice a week to participate in text discussions and receive information.

WebCT was used to exchange information that had some of the following characteristics:

- Reference information such as the schedule, resource URLs, and technical tips

- Reading materials, chosen by conversation facilitators, for prior or follow-up reading

- Participant questions and reflective comments regarding weekly conversation topics

- Participant resource sharing (URLs, documents, journal or book references)

Proceedings of the 2004 American Society for Engineering Education Annual Conference \& Exposition

Copyright 2004 American Society for Engineering Education 
- Downloadable versions of the teleconference slides, including some of the interactive annotations made during the live sessions

- Projects at the end of the experience

** Note: The WebCT tools used during this online experience are commonly found in other Course Management System applications. The University of Wisconsin-Madison is now implementing a new Course Management System (using Desire2Learn technology) that will replace the use of WebCT on its campus.

The technical requirements to participate in this experience included a relatively recent PC, monitor, and browser $(200 \mathrm{MHz}, 800 \times 600$ screen resolution, IE 5 or higher) and a minimum of $56 \mathrm{k}$ internet connection.

A portion of the in-person orientation took place in a computer lab, to familiarize the group with the communication technologies they would use on return to their campuses. Faculty participated in a hands-on demonstration of WebCT and participated from their hotel rooms in a teleconference session to simulate the distance learning part of their experience.

The combination of real-time and asynchronous options:

- allowed faculty to participate both on a scheduled basis, and on their own time.

- increased participants' experience in using web-based communication tools for teaching and learning

- continued the momentum of personal collegial connection initiated at the inperson meeting.

- provided the means for a professional development experience to take place over months with fewer scheduling restrictions and travel requirements than periodic in-person meetings

- Provided an alternative to short, focused professional development options, such as conferences and seminars

\section{Evaluation}

The overall goals of the evaluation of Ways of Knowing, Ways of Practice were 1) to determine the degree to which the online delivery mode positively impacted faculty professional development and 2) to better understand the feasibility of an online delivery mode for faculty professional development. Feedback from four sources was used to evaluate these goals:

- Participants

- Individual journal observations from participants in terms of their learning and the value and meaning of this experience (initial, mid, final)

- Scaled items reflecting the expected outcomes for the experience (initial, mid, final)

- Evaluation of the orientation in Madison (initial)

- Evaluation of the entire experience (final)

- Facilitator and design team 
- Process feedback regarding this approach to faculty development (4-6 weeks into the semester-March)

- Outcome evaluation at end of semester

- Evaluator's observations throughout and at the end of the semester

- Other critical people

- Initial feedback from Foundation Coalition and Dean of the College of Engineering. In the case of the Dean, the purpose was to obtain perspective on what is needed to make a future decision regarding the value of this type of approach to professional development

- Other sources of data to determine level of engagement and development of a learning community throughout the semester

- Attendance

- Progress on participant investigations (projects)

- Time and costs involved

- Follow-up with participants (3-6 months) to determine longer term impact from experience

An analysis of the feedback obtained, in addition to the financial data, showed that overall, the pilot provided an opportunity to learn more about how to use an alternative mode of delivery such as an on-line experience to deliver quality professional development, to build a community of teachers committed to learning, and to provide an alternative professional development activity. Key findings showing the value of this online professional development experience according to its impact on faculty and its feasibility as an effective method of professional development are summarized below:

\section{Impact on Faculty Members}

- $100 \%$ retention and high participation at individual sessions throughout the course indicates fulfilling a need

- High number of faculty participants indicated that they would recommend this experience to a colleague

- Short term impact on changes indicate that the experience confirmed more than changed (similar, predisposed group) the use of effective methodologies and curriculum design

- Evidence from faculty to suggest that experience will carry over to other things for them

- Evidence from faculty to suggest that people will change because of this online experience

- Evidence from faculty to demonstrate how faculty research what others have done in similar situations related to teaching and learning

On line Delivery Mode

- Relatively free of technical difficulties throughout the experience

- Comments from faculty indicate that this was a good way to deliver a course such as this

- Convenient and efficient technology that worked well 
- Discussion in online course mode worked well, although it could be improved also

- $\quad$ Relatively cost effective--- $\$ 88,000 / 20$ participants $=\$ 4400$ per participants (Figure 2, Table 1)

Figure 2: Cost Breakdown

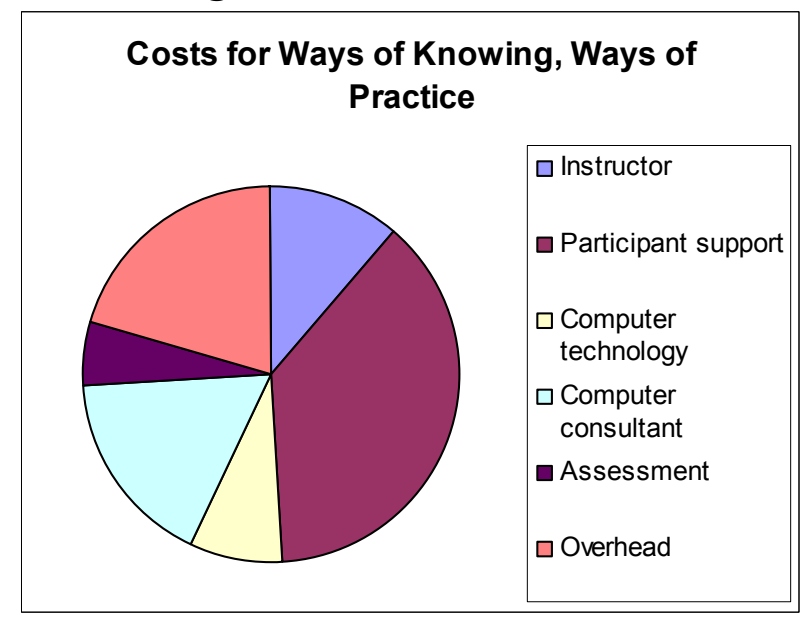

Table 1. Project Costs

\begin{tabular}{|l|l|}
\hline Cost & Money \\
\hline Participants & \\
\hline Orientation & $\$ 15,000$ \\
\hline Honorarium & $\$ 18,000$ \\
\hline Computer Consultant & $\$ 15,000$ \\
\hline Instructor & $\$ 10,000$ \\
\hline Computer Technology & $\$ 7,000$ \\
\hline Assessment & $\$ 5,000$ \\
\hline Overhead & $\$ 18,000$ \\
\hline TOTAL & $\mathbf{\$ 8 8 , 0 0 0}$ \\
\hline
\end{tabular}

\section{Lessons Learned}

Many lessons were learned as part of this pilot. They confirm the importance of nine characteristics:

- Paying attention to process issues: Building on participants' individual issues, exploring a research base for similar situations, finding resources, discussing context and issues among peers, and working collaboratively to solve the issue.

- Having an initial orientation where people can meet each other before they have an online experience

- Structuring the discussions so that they reflect active learning strategies

- Having appropriate content

- Having up-to-date technical capabilities

- Having a knowledgeable facilitator and teaching team

- Continuing to improve the discussion process on-line.

Proceedings of the 2004 American Society for Engineering Education Annual Conference \& Exposition 
- Continuing team component with one engineering faculty and one science, math, or technology faculty member for inter-disciplinary benefits.

- Continuing research-based approach both for learning what others have done in similar situations and for investigating specific teaching and learning situations.

\section{Conclusions}

The Ways of Knowing: Ways of Practice on-line experience offered an alternative to better integrate these types of activities into the more regular part of the life of faculty. The many positive comments from both participants and the teaching team suggest that the on-line experience produced significant value for the participants. The overall value of the experience can be stated in five areas:

- Confirming and enriching the teaching philosophy and practices that many participants already shared prior to the on-line experience

- Building a community of teachers committed to improving their own teaching and learning styles

- Having the opportunity to exchange ideas regarding teaching and to learn with colleagues from around the country

- Affirming legitimacy of sharing information about teaching

- Providing an opportunity for professional development for both individual faculty members and their institution

It is perhaps overly ambitious to expect to see major and substantive changes from an online experience such as this one, especially given the participants' more homogeneous nature and mostly predisposed attitude towards active learning. However, this does not negate the importance of such experiences. Nor does it negate the importance of continuing to develop on-line experiences such as this one.

\section{Recommendations}

Key recommendations to integrate professional development into faculty expectations and workload include:

1. Adapt this model of online professional development as appropriate. Build on the lessons gained from Ways of Knowing/Ways of Practice.

2. Target newer faculty for this type of online experience.

3. Develop mechanisms to provide faculty and administrators incentives to better integrate professional development into faculty expectations and workload. For example, recognize the importance of providing faculty participants with an honorarium as an indicator of institutional support.

4. Monitor the learning styles of the participants more closely to determine whether the on-line experience is more appropriate for some individuals than for others.

5. Conduct follow-up assessment with participants to better determine impact of this experience both on the individual and the project.

6. Actively seek funding to ensure continuation of this type of on-line experience within the College of Engineering at the UW-Madison. 


\section{Acknowledgements}

We acknowledge the support of the Foundation Coalition, an NSF-funded project of the Engineering Education Program, Award Number EEC-9802942. This project has demonstrated the effectiveness of an on-line professional development experience for engineering faculty. The learning outcomes identified above are indicators of a learning organization; participating institutions can be described as learning organizations based on the contributions of their faculty.

http://www.engr.wisc.edu/services/elc/waysknow.htm.

\section{Bibliography}

1. Schön, D. Educating the Reflective Practitioner. San Francisco, CA: Jossey-Bass Inc., 1987.

2. Argyris, Chris. Knowledge for Action: A Guide to Overcoming Barriers

Organizational Change. San Francisco, CA: Jossey-Bass Inc., 1993.

3. Wenger, E., R. McDermott, and W. Snyder. Cultivating Communities of Practice.

Cambridge, MA: Harvard Business School Press, 2002.

4. Senge, Peter M. Schools That Learn. New York: Currency Doubleday, 2000.

5. Bransford, J.D., A.L. Brown, and R.R. Cocking, eds. How People Learn: Brain, Mind, Experience, and School. Washington, DC: National Academy Press, 1999.

6. Hildreth, Paul, C. Kimble. Knowledge Networks: Innovation through Communities of Practice. Idea Group Publishing, 2004.

\section{Biographical Information}

SANDRA SHAW COURTER is director of the Engineering Learning Center at the University of Wisconsin - Madison. She was the learning guide for the project and teaches technical communication as a member of the Department of Engineering Professional Development

CIDNEY FREITAG is an information systems consultant with the Division of Information Technology at the University of Wisconsin - Madison. She was the technology guide for the project and consults with faculty and staff who wish to integrate technology into their classroom.

MARY MCENIRY is a consultant who specializes in assessment at the University of Wisconsin Madison. She was the evaluation guide for the project and consults with faculty and staff who design classroom research projects. 